\title{
Evidence that BMI and type 2 diabetes share only a minor fraction of genetic variance: a follow-up study of 23,585 monozygotic and dizygotic twins from the Finnish Twin Cohort Study
}

\author{
M. Lehtovirta • K. H. Pietiläinen • E. Levälahti • \\ K. Heikkilä • L. Groop • K. Silventoinen • \\ M. Koskenvuo • J. Kaprio
}

Received: 6 January 2010 / Accepted: 12 March 2010/Published online: 17 April 2010

(C) Springer-Verlag 2010

\begin{abstract}
Aims/hypothesis We investigated whether BMI predicts type 2 diabetes in twins and to what extent that is explained by common genetic factors.

Methods This was a population-based twin cohort study. Monozygotic $(n=4,076)$ and dizygotic $(n=9,109)$ nondiabetic twin pairs born before 1958 answered a questionnaire in 1975, from which BMI was obtained. Information on incident cases of diabetes was obtained by linkage to nationwide registers until 2005.

Results Altogether, 1,332 twins $(6.3 \%$ of men, $5.1 \%$ of women) developed type 2 diabetes. The HR for type 2 diabetes increased monotonically with a mean of $1.22(95 \%$ CI 1.20-1.24) per BMI unit and of 1.97 (95\% CI 1.87-
\end{abstract}

\footnotetext{
M. Lehtovirta $(\bowtie) \cdot K$. H. Pietiläinen • E. Levälahti • K. Heikkilä $\cdot$ K. Silventoinen $\cdot$ M. Koskenvuo $\cdot$ J. Kaprio Department of Public Health, University of Helsinki, P.O. Box 41, FIN-00014 Helsinki, Finland e-mail: mikko.lehtovirta@helsinki.fi

K. H. Pietiläinen

Obesity Research Unit, Department of Psychiatry, University of Helsinki,

Helsinki, Finland

L. Groop

Diabetes and Endocrinology Research Unit,

CRC Malmö University Hospital, Lund University,

Malmö, Sweden

J. Kaprio

Department of Mental Health and Alcohol Research,

National Public Health Institute,

Helsinki, Finland

2.08) per SD of BMI. The HRs for lean, overweight, obese and morbidly obese participants were $0.59,2.96,6.80$ and 13.64 as compared with normal weight participants. Model heritability estimates for bivariate variance due to an additive genetic component and non-shared environmental component were $75 \%$ (men) and $71 \%$ (women) for BMI, and $73 \%$ and $64 \%$, respectively for type 2 diabetes. The correlations between genetic variance components $\left(r_{\mathrm{g}}\right)$ indicated that one fifth of the covariance of BMI and type 2 diabetes was due to shared genetic influences. Although the mean monozygotic concordance for type 2 diabetes was approximately twice the dizygotic one, age of onset of diabetes within twin pair members varied greatly, irrespective of zygosity.

Conclusions/interpretation A 28-year follow-up of adult Finnish twins showed that despite high trait heritability estimates, only a fraction of covariation in BMI and incident type 2 diabetes was of genetic origin.

Keywords Body mass index · Follow-up studies .

Proportional hazards models · Twins .

Type 2 diabetes mellitus

$\begin{array}{ll}\text { Abbreviations } \\ \text { A } & \text { Additive genetic component } \\ \mathrm{C} & \text { Shared environmental component } \\ \mathrm{D} & \text { Genetic effects due to dominance } \\ \mathrm{E} & \text { Non-shared environmental component } \\ -2 \mathrm{LL} & \text { Minus two times log likelihood test } \\ r_{\mathrm{e}} & \text { Correlation between environmental variance } \\ & \text { components } \\ r_{\mathrm{g}} & \text { Correlation between genetic variance components }\end{array}$




\section{Introduction}

The increasing prevalence of type 2 diabetes seems to follow that of obesity. It has been estimated that arresting weight increase would prevent type 2 diabetes in six out of ten cases [1]. However, the extent to which this kind of association is dependent upon genes influencing BMI and type 2 diabetes is not clear. What is known is that interindividual variability in the magnitude of weight gain is accounted for by genes [2]. On the other hand, it is not clear how the increase in BMI under positive energy balance translates into increased incidence of type 2 diabetes mellitus. In theory, type 2 diabetes could result either: (1) solely from obesity, i.e. through action of obesity genes, under other plausible non-genetic influences; or (2) from the simultaneous but independent action of diabetes and obesity genes. In other words, obesity and type 2 diabetes may share $100 \%$ (in the first instance) or $0 \%$ (in the second instance) of their genes. The reality probably lies between these extremes.

The results from several recent genome-wide association studies have identified at least 18 genes consistently associated with type 2 diabetes [3]. After the initial discovery of FTO and MC4R genes, 15 new loci have so far been found for BMI $[4,5]$. However, the compiled contribution of the numerous known allelic regions to the risk of type 2 diabetes is only in the region $10 \%$ to $15 \%$ [6] and that for risk of obesity only a few per cent $[4,5]$. FTO is one of the few genes that have been found to influence BMI and risk of type 2 diabetes [7, 8]. Thus, contrary to earlier expectations, confirmation of the existence of major genetic factors behind type 2 diabetes and obesity, or shared by them has proven to be a challenging task. In addition to allelic variations, copy number variation, epigenetic changes and gene-gene interaction may contribute to susceptibility to obesity and type 2 diabetes [3]. It is therefore unlikely that molecular genetic methods will be able to uncover the complete genetic make-up in the foreseeable future. To this end, quantification of the impact of common genes and environmental factors using genetic epidemiology models helps understand the nature of complex disorders such as obesity and diabetes [9].

According to cross-sectional twin and family studies, $20 \%$ to $30 \%$ of the covariance between BMI and type 2 diabetes could be due to shared genes [10,11]. In such studies, however, the nature of the observed association between obesity and type 2 diabetes may have been biased due to the increased mortality rates associated with both conditions. The inability to control for the influence of excess mortality may lead to underestimation of the presence of shared genes. A longitudinal study of population representative samples, on the other hand, helps to reduce the influence of such bias.
The aim of the current study was to use a large population-based cohort of adult Finnish twins with an almost 30 year follow-up to test whether BMI predicts the onset of type 2 diabetes and, especially, to what extent shared genetic influences explain this association.

\section{Methods}

Participants The Finnish Twin Cohort Study is a programme for the study of genetic and environmental determinants of chronic diseases and their risk factors [9, 12]. A baseline questionnaire was distributed in 1975 to same-sex twin pairs born before 1958, with an individual response rate of $89 \%$. Twin zygosity was determined in 1975 by examining the responses of both members of each pair to two questions on similarity of appearance at primary school age. A set of decision rules was used to classify $93.1 \%$ of the twin pairs as monozygotic or dizygotic; $6.9 \%$ of twin pairs remained undetermined. The questionnaire method has been shown to be highly accurate in a validation study using genetic markers [13].

The participants were informed about the purposes of the overall cohort study at the baseline questionnaire in 1975 and in conjunction with the subsequent questionnaires received by cohort members. In responding to the questionnaire, participants also gave informed consent. The record-linkages were also approved by the appropriate authorities responsible for the registers, the data-protection ombudsman and the Ethics Committee of the Department of Public Health, University of Helsinki.

The twins were asked to provide their current weight $(\mathrm{kg})$ and height $(\mathrm{cm})$, which were used to assess their BMI $\left(\mathrm{kg} / \mathrm{m}^{2}\right)$ at baseline. The validity of the self-reported BMI was tested in a subsample of twins (100 men, 125 women) from the same cohort by first asking them to provide weight and height in a questionnaire in 1990 and then weighing and measuring them between 1992 and 1993. The correlation coefficients between self-reported and measured BMI in men and women were 0.89 and 0.90 , respectively [14].

For the present study, data on incidence of type 2 diabetes in twins between 1976 and 1987 were first collected through computerised record linkage based on the unique personal ID assigned to all Finns, from death certificates, the National Hospital Discharge Register and the Medication Register of the Social Insurance Institution. The results were published in 1992 [15]. The same information resources were used to gather information on new incident cases of diabetes between 1988 and 1995 in the same cohort of twins. These data were examined by two research physicians, using the same classification of diabetes as in the earlier report, to determine a date for the diagnosis. Finally, a computerised linkage to the 
Medication Register was performed in 2006 to update the information on all medical certificates for diabetes in the twin cohort between 1996 and 2004. The data thus collected included only a general diagnosis of diabetes, birth date and the date of certificate admission. As all study participants were 38 years or older in 1996, it was assumed that all of them had type 2 diabetes and that the date of diagnosis was the date of certification. Individuals with diabetes in 1975, based upon questionnaire or retrospective register-linkage, were excluded from the analysis. Data on vital status during follow-up was obtained from the Population Register Centre of Finland, which holds information on deaths, migration or current address in Finland.

The possibility of classifying patients with type 1 diabetes as type 2 diabetes patients in our database is small. From the medical certificates available until 1995 for the current twin cohort, we assessed that the proportion of type 2 diabetes was $90.0 \%$ in the years 1976 to 1987 and $97.9 \%$ in the years 1988 to 1995 , respectively. After 1995, the proportion is likely to be even higher. Similar conclusions could be made on the basis of population indices of diabetes in Finland in 2005, where 96.5\% of 45to 64-year-old patients had type 2 diabetes [14]. To assess possible misclassification error, background population incidences of type 1 and 2 diabetes mellitus in Finland in 2005 were determined as follows. In the 30 - to 44 -year age group, the incidence of type 1 and type 2 diabetes were 17 and $83 / 100,000$; in the 45 - to 64 -year age group, incidence was 18 and 491/100,000, respectively. Taken together, it can be said that although a fraction of the cases after 1995 were cases other than type 2 diabetes, the admixture was trivial with regard to analysis of the effect of BMI.

The compilation of the actual dataset used to estimate HRs, twin correlations and variance components is shown in Fig. 1. After removing participants with diabetes at baseline or those who had undefined zygosity (mainly due to non-response to the questionnaire), or had moved abroad or died before 1 January 1976, self-reported BMI data were available for 23,585 of the 32,860 twins originally identified. The number of complete pairs was 10,400 . In addition, there were 2,785 twins (401 monozygotic men, 377 monozygotic women, 1,115 dizygotic men and 892 dizygotic women) without a co-twin.

Data analysis and statistical methods All individuals were used in the analyses of HR and all pairs in the analyses of concordances, twin correlations and variance components of type 2 diabetes.

Cox proportional hazard regression was used to estimate the relative risk of incident type 2 diabetes by categories of BMI (underweight $<18.5 \mathrm{~kg} / \mathrm{m}^{2}$; normal weight 18.5 to

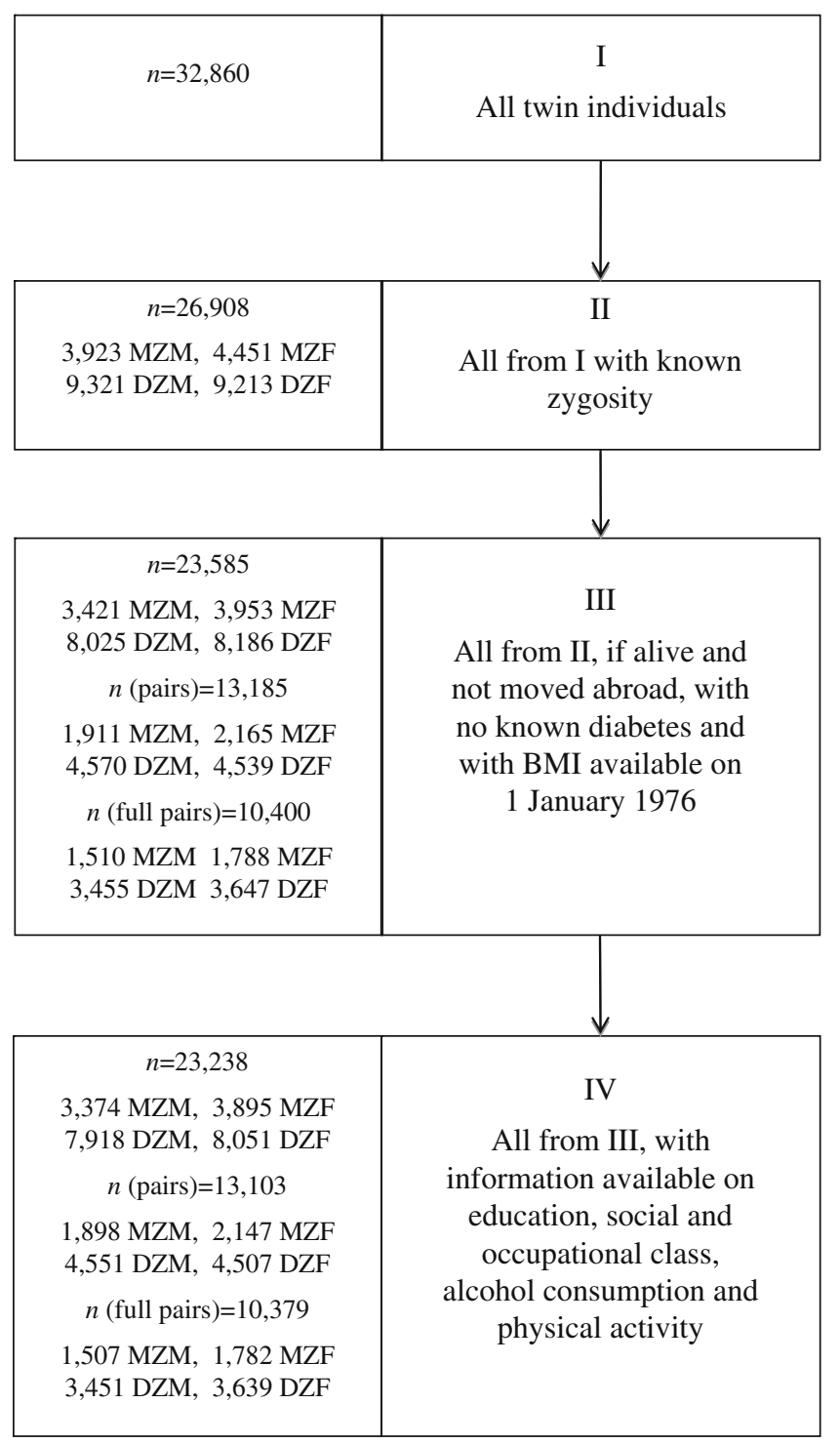

Fig. 1 Compilation of the study population. DZF, dizygotic female; DZM, dizygotic male; MZF, monozygotic female; MZM, monozygotic male

$24.9 \mathrm{~kg} / \mathrm{m}^{2}$; overweight 25 to $29.9 \mathrm{~kg} / \mathrm{m}^{2}$; obesity 30 to $34.9 \mathrm{~kg} / \mathrm{m}^{2}$; and morbid obesity $\geq 35 \mathrm{~kg} / \mathrm{m}^{2}$ and over), by integer values of BMI, as well as per unit BMI and per SD of BMI. For type 2 diabetes cases, follow-up ended at the date of diagnosis, while other participants were censored at the time of death, migration from Finland or end of followup (31 December 2004). Regression models were adjusted for age and sex only, as well as for additional covariates. Standard errors and $p$ values were corrected for clustering of twins within twin pairs in analyses of individuals. The proportionality assumption was evaluated by plotting of $\log -\log$ of survival probability against $\log$ (time). The parallelism of the curves was good, although it diminished somewhat at the very highest ages. Pairwise (the number of 
pairs concordant for type 2 diabetes divided by the number of pairs either concordant or discordant for type 2 diabetes) and probandwise (the proportion of twins with diabetes among the co-twins of twins with diabetes) concordance rates were estimated as described in our previous report [15].

Sex-specific genetic univariate models were first tested for BMI and type 2 diabetes. Models were fitted to the data, assuming that variation in the phenotypes were attributable to a combination of a non-shared environmental component (E), a shared environmental component (C), an additive genetic component (A) and genetic effects due to dominance (D). The estimates were calculated as the proportion of variance divided by the total variance. The superiority of alternative, hierarchically nested models was tested by minus two times log likelihood test $(-2 \mathrm{LL})$ with $d f$ equal to the differences in $d f$ of the models to be compared. The relative proportion of $\mathrm{A}$ in relation to the total trait variance was also the estimate of heritability, $h^{2}$. Age-adjusted bivariate genetic factor models were then estimated separately for male and female twin pairs, with mean and variance weighted least squares method (WLSMV) implemented in MPlus software (MPlus version 5; www.statmodel.com, accessed 18 December 2008). Bivariate models included age- and Box-Cox-transformed BMI as a continuous trait and type 2 diabetes as a dichotomous trait, and yielded, in addition to the variance components, the coefficients for phenotypic $(r)$, intraclass (IC) correlation between genetic variance components $\left(r_{\mathrm{g}}\right)$ and correlation between environmental variance components $\left(r_{\mathrm{e}}\right)$. The bias-corrected 95\% CIs were estimated using a bootstrap method with 1000 draws.

\section{Results}

BMI and the risk of developing type 2 diabetes The phenotypic correlation between BMI and type 2 diabetes was 0.40 in men and 0.38 in women. The overall HR of type 2 diabetes was 1.22 (95\% CI 1.20-1.24) per BMI unit and $1.97(95 \%$ CI $1.87-2.08)$ per 1 SD of BMI, respectively (Fig. 2). Altogether 1332 twin individuals ( $6.3 \%$ of men, $5.1 \%$ of women) developed type 2 diabetes by the end of the follow-up, with no significant difference in zygosity (HR for dizygotic twin individuals $0.93,95 \%$ CI $0.82-1.06$ ). The HR of developing type 2 diabetes increased monotonically from 1.00 (normal weight) to 13.6 (morbid obesity, BMI $\geq 35 \mathrm{~kg} / \mathrm{m}^{2}$ ), when age, sex, physical activity, alcohol consumption, educational status and social class, respectively, were all used as covariates (Table 1).

The single twins (those without a co-twin) had higher BMI than the twins belonging to complete pairs (23.9 vs 23.1, $p<0.0001)$. Accordingly, the HR for type 2 diabetes was 1.31 among single twins, as compared with complete

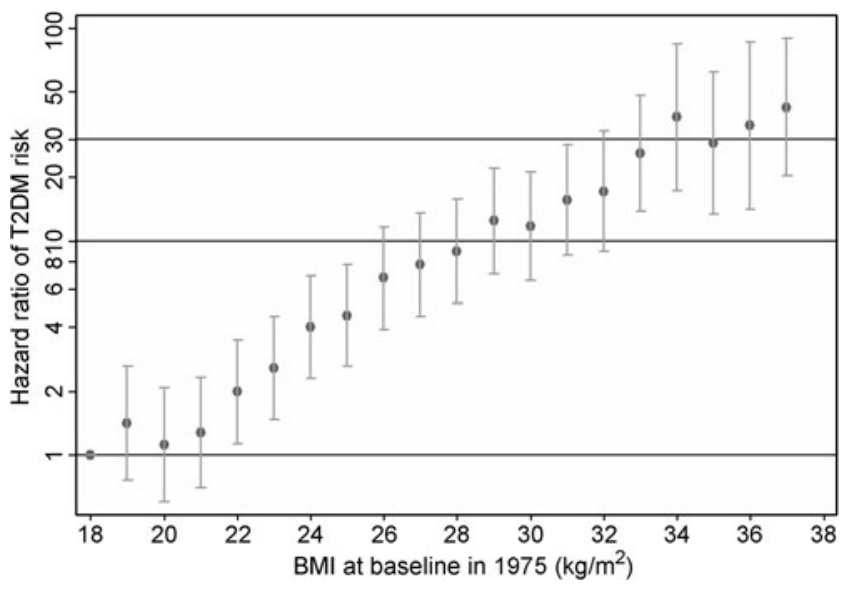

Fig. 2 The risk (Cox proportional hazards model) of developing type 2 diabetes (T2DM) (logarithmic scale) plotted against self-reported BMI recorded in 1975 during follow-up of 21,933 twins between 1975 and 2005, with respective 95\% CIs (whiskers). Due to small numbers at the extremes of BMI distribution, participants with $\mathrm{BMI} \leq$ $18 \mathrm{~kg} / \mathrm{m}^{2}$, or $\mathrm{BMI} \geq 37 \mathrm{~kg} / \mathrm{m}^{2}$ more were pooled in two groups respectively. Age, sex, educational level, occupation, social class, physical activity and alcohol consumption were used as covariates

pairs. Therefore, we calculated the HR per BMI unit separately for single twins (those without a co-twin) and complete pairs. The HR was 1.22 (95\% CI $1.18-1.26)$ among single twins and 1.23 (95\% CI 1.21-1.25) among complete pairs, respectively. In other words, no difference in the BMI-associated risk of type 2 diabetes was observed between twins from incomplete vs those from complete pairs. Participants who were excluded due to insufficient information being available $(n=9275)$ were older than $(39.3 \pm 0.2$ vs $35.6 \pm 0.1$ years, $p<0.0001)$, but their BMI did not differ from that of $(23.7 \pm 0.1$ vs $23.2 \pm 0.0, p=0.50)$ the twins included in the analysis.

Concordance rates for type 2 diabetes during follow-up At 0.41 proband-wise and 0.34 pairwise, the monozygotic concordance rates were higher than those in dizygotic twins ( 0.19 and 0.12 , respectively). Over the follow-up period, approximately half of the monozygotic twins and a third of the dizygotic twins with an affected co-twin developed type 2 diabetes (Fig. 3). The mean age at start of follow-up, sex or the age at which twin 1 was diagnosed with type 2 diabetes were not significant predictors in the Cox regression model of type 2 diabetes in the co-twins of a twin in whom type 2 diabetes was already present.

Correlations and variance components The intraclass correlations for monozygotic were roughly twice those for dizygotic twins (Table 2$)$ for BMI (0.71 in monozygotic men and women, 0.41 in dizygotic men, 0.36 in dizygotic women) and for type 2 diabetes ( 0.74 in monozygotic men, 0.63 in monozygotic women, 0.34 in dizygotic men and 
Table 1 The number of individuals categorised to BMI $\left(\mathrm{kg} / \mathrm{m}^{2}\right)$ classes together with the number of incident cases of type 2 diabetes in each class

\begin{tabular}{lcccc}
\hline BMI class $\left(\mathrm{kg} / \mathrm{m}^{2}\right)$ & $\begin{array}{l}\text { Individuals at } \\
\text { baseline }(n)^{\mathrm{a}}\end{array}$ & $\begin{array}{l}\text { Incident cases of } \\
\text { type 2 diabetes }(n)\end{array}$ & $\mathrm{HR}^{\mathrm{b}}$ & $\mathrm{HR}^{\mathrm{c}}$ \\
\hline All classes & 23,585 & 1,332 & $0.56(0.29-1.04)$ & $0.59(0.31-1.11)$ \\
Underweight $(<18.5)$ & 1,123 & 10 & 1.00 & 1.00 \\
Normal weight $(18.50-24.99)$ & 16,216 & 446 & $3.05(2.67-3.48)$ & $2.96(2.59-3.39)$ \\
Overweight $(25.00-29.99)$ & 5,314 & 625 & $7.17(5.97-8.60)$ & $6.80(5.62-8.22)$ \\
Obese $(30.00-34.99)$ & 835 & 210 & $14.02(9.58-20.51)$ & $13.64(9.28-20.05)$ \\
Severely obese $(\geq 35.00)$ & 97 & 41 & & \\
\hline
\end{tabular}

${ }^{\text {a }}$ Baseline 1975

${ }^{\mathrm{b}} \mathrm{HR}$ for the risk of developing type 2 diabetes, adjusted for age and sex as covariates

${ }^{\mathrm{c}}$ HR for the risk of developing type 2 diabetes adjusted for age, sex, physical activity, alcohol consumption, educational status and social class as covariates

women, respectively). In univariate analyses of BMI and type 2 diabetes in women, and of type 2 diabetes in men, the AE model fitted the data best. For BMI in men, the ACE model fitted the data slightly better than the AE model ( $p=0.005$, difference $-2 \mathrm{LL}=8.06$ with $d f=1$ ), but the proportion of the $\mathrm{C}$ component was no more than 0.10 (95\% CI 0.00-0.25). Therefore, the bivariate AE model was finally selected for both sexes. According to the model, $75 \%$ and $71 \%$ of the variance in BMI in men and women respectively could be attributed to additive genetic influences. Accordingly for type 2 diabetes, additive genetic factors accounted for $73 \%$ of the total variation in disease susceptibility in men and for $64 \%$ in women. The modelbased $r_{\mathrm{g}}$ of 0.40 in men and 0.45 in women implied that genetic covariation with BMI explained $16 \%$ (men) and

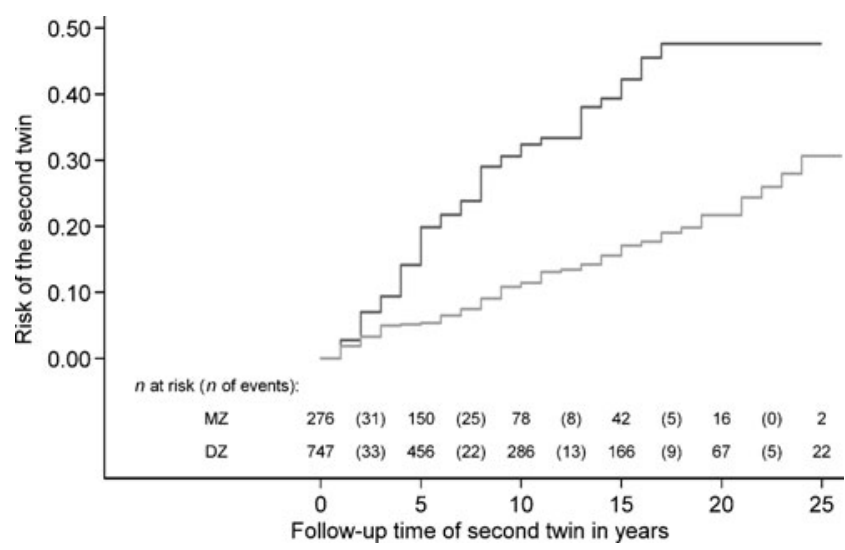

Fig. 3 The relative risk (\%) of the non-diabetic co-twin within pairs discordant for type 2 diabetes as a function of follow-up time. $n$ values for $\mathrm{MZ}$ and $\mathrm{DZ}$ indicate number at risk (number of events) during each interval. Black line, monozygotic; grey line, dizygotic. The respective mean age on 1 January 1976 at start of follow-up was 42.1 years for monozygotic and 42.9 years for dizygotic twins, respectively. Twins who died or moved abroad or were lost to followup were taken into account in the calculation of risk
$21 \%$ (women) of the genetic covariance for type 2 diabetes. The coefficients for $r_{\mathrm{e}}$ (men 0.37 , women 0.22 ) were slightly lower than those for $r_{\mathrm{g}}$.

\section{Discussion}

To our knowledge, this is the first population-based followup study on the cumulative incidence of type 2 diabetes among twin pairs. With more than 10,000 adult monozygotic and dizygotic twin pairs from the Finnish Twin Cohort Study we show how well even a single estimate for BMI predicted future type 2 diabetes. Diabetes risk was almost 14-fold greater among morbidly obese (BMI $\geq 35 \mathrm{~kg} /$ $\mathrm{m}^{2}$ ) than among normal-weight participants. Our study also illustrates that, although BMI and type 2 diabetes had high heritability, only a minor proportion of their covariance was explained by shared genetic factors.

As a confirmatory outcome, we observed a monotonous increase in HR for type 2 diabetes between BMI 20 and $38 \mathrm{~kg} / \mathrm{m}^{2}$. Similar findings were seen in 1995 in the US Nurses Study [16]. In general, the HR for type 2 diabetes was in line with previous reports. The age and sex adjusted HR values in our study were well in line with the respective values in a population-based follow-up study from Glasgow [1]. The increase in risk per BMI unit of 1.97 was in line with the pooled relative risk of 1.87 in a large meta-analysis published in 2007 [17]. In our study the HR for type 2 diabetes in severely obese participants was as much as 14 times that for all normal-weight participants, while it increased from 1 to 30 between BMI 20 and 35 when analysed per BMI unit with the low end of normal weight as reference category. Our study therefore supports the view that, in the prevention of type 2 diabetes, weight control is essential and also beneficial within BMI ranges considered to be normal.

Although earlier cross-sectional studies differed from ours with regard to recruitment of study participants, 
Table 2 Results from the sex-specific bivariate genetic AE model including age and Box-Cox-transformed BMI as continuous, and type 2 diabetes as dichotomous variables

\begin{tabular}{lllllll}
\hline $\begin{array}{l}\text { Participants } \\
\text { by sex }\end{array}$ & VA BMI & $\begin{array}{l}\text { VA type 2 diabetes } \\
\text { mellitus }\end{array}$ & VE BMI & $\begin{array}{l}\text { VE type 2 diabetes } \\
\text { mellitus }\end{array}$ & $r_{\mathrm{g}}$ & $r_{\mathrm{e}}$ \\
\hline Men & $0.75(0.71-0.78)$ & $0.73(0.64-0.81)$ & $0.25(0.22-0.29)$ & $0.27(0.20-0.36)$ & $0.40(0.31-0.48)$ & $0.37(0.18-0.59)$ \\
Women & $0.71(0.68-0.75)$ & $0.64(0.52-0.74)$ & $0.29(0.25-0.32)$ & $0.36(0.27-0.48)$ & $0.45(0.35-0.54)$ & $0.22(0.05-0.38)$ \\
\hline
\end{tabular}

Sex-specific estimates for additive genetic (VA) and non-shared environmental (VE) variance components, as well as coefficients of correlations as indicated for BMI and type 2 diabetes

Values in parentheses are bias-corrected 95\% CIs

absence of follow-up, and ascertainment and prevalence of type 2 diabetes, they all resulted in surprisingly similar $r_{\mathrm{g}}$ estimates between BMI and diabetes, e.g. 0.55 in the Strong Heart Family Study [10] and 0.46 in a recent Australian twin study [11]. In the Strong Heart Family Study with 950 adults from 32 extended families of American-Indian ancestry, the prevalence of diabetes was substantial, namely $30 \%$. In the Australian study, the prevalence of type 2 diabetes was only $0.34 \%$, with only 113 of the nearly 20,000 pairs screened having type 2 diabetes in one or both twins. The similarity in $r_{\mathrm{g}}$ can be taken to indicate that only a portion of the genes that contribute to BMI and type 2 diabetes mellitus are the same.

While the ratio of the risk of type 2 diabetes in siblings of patients with the disease compared with disease risk in the general population has varied between 3 and 4 [18], genome-wide association studies have estimated the $\lambda$ attributable to all loci for type 2 diabetes to be only little above one, i.e. these loci have been estimated to explain 5 to $10 \%$ of the inherited predisposition [19]. As the FTO gene appears to increase diabetes risk mainly via obesity [20], no gene accounting for the observed $r_{\mathrm{g}}$ between BMI and type 2 diabetes exists at present. Of the genes found for BMI, a significant proportion act through the central nervous system [4, 5], whereas most diabetes genes implicate pancreatic beta cell function or insulin resistance [3]. In other words, despite the strong association between diabetes risk and obesity, only part of this association is explained by genetic similarity. Thus although new genetic influences between adiposity and type 2 diabetes will emerge, the odds for finding a major gene accounting for obesity and type 2 diabetes have decreased.

Our heritability estimates for BMI were in line with previous studies $[14,16]$. Although the respective estimates for type 2 diabetes appeared high, they were, under an $\mathrm{AE}$ model, similar to our earlier report [15]. That is to say, due to longer follow-up time, new cases of diabetes had emerged, but at parallel rates among monozygotic and dizygotic twins. The extension of follow-up time enabled us to view the longitudinal development of concordance for type 2 diabetes among monozygotic twins. Interestingly, it took more than a decade for type 2 diabetes concordance in monozygotic twins to reach 0.5 , although the members of each pair share all their genes and childhood environments. In other words, for the risk of developing type 2 diabetes, current individual lifestyle-related behaviour, which is embedded in the variance component $\mathrm{E}$, is more important than the past childhood family environment (variance component C). At the onset of the current study, less than $5 \%$ of the twins reported having lived with their co-twin after the age of 25 years (data not shown). Lack of influence of shared environment after adolescence has been observed, among other things, for food use [21], BMI [22] and physical activity [23].

The main virtue of our study is that it is a large, population-based study cohort with long follow-up of all available twin pairs. As pointed out by Poulsen in 1999, clinic-based studies tend to be biased due to disproportionate sampling of concordant and monozygotic pairs, as well as the tendency to include more severe cases of diabetes, thus increasing the possibility of reporting higher concordance rates among monozygotic twins [24]. We aimed to avoid this bias by using information from all available pairs. The long follow-up of a population-based twin cohort in our study also enabled coverage of the near-life-time risk of type 2 diabetes, hence improving the possibility of detecting diabetes cases that would have remained unnoticed in a cross sectional set-up. The prospective study design, moreover, enabled us to steer clear of problems of information loss due to study participants not attending follow-up visits, as has been the case for most cohort studies of type 2 diabetes incidence [18]. Thus, the combination of a large population-based twin sample, together with the nationwide diabetes medication register, provides at least as reliable tools for the study of type 2 diabetes epidemiology as any of the smaller scale studies using direct measurement of blood glucose values.

The limitations of our study include self-reported BMI values and variability in the diagnosis of type 2 diabetes. As mentioned above, we had previously shown that selfreported BMI values were well in line with measured ones within the same twin cohort [14]. The prospective study 
design also reduced the bias of reporting weight and avoided the problem of weight change after type 2 diabetes diagnosis. Moreover, in the current twin cohort the genetic influences on weight change have already been shown to be virtually uncorrelated with the genetic effects on BMI [25]. The diagnostic criteria for type 2 diabetes changed between 1975 and 2005 with regard to name (adult-onset diabetes mellitus, non-insulin-dependent diabetes mellitus, type 2 diabetes mellitus) and clinical definition [26]. However, all medical records were reviewed in detail and recoded up to 1995. After that, misdiagnosis between type 1 and type 2 diabetes played a minor role as even the youngest twins were at least 38 years old when the latest compilation of diabetes was begun. Finally, although the twins without a participating co-twin were more obese than those from complete pairs, the association between BMI and risk of type 2 diabetes remained unchanged in both groups.

Summary Four salient findings emerged from this 28-year follow-up of 23,585 twins from the Finnish Twin Cohort Study. First, the risk of developing type 2 diabetes increased monotonically at levels already within the normal BMI range. Second, there was huge variability in the age at onset of type 2 diabetes, even within genetically identical twins. Third, the most parsimonious bivariate model suggested high additive genetic variance components for BMI and type 2 diabetes. Finally, shared genetic influences explained about one fifth of the covariation of BMI and type 2 diabetes.

Conclusions Our data add to evidence that BMI is a strong risk factor for future type 2 diabetes, even in individuals with normal weight. While there are some shared genetic factors between BMI and type 2 diabetes, many genetic influences are specific either to BMI or to type 2 diabetes.

\begin{abstract}
Acknowledgements This study was supported by The Academy of Finland Centre of Excellence in Complex Disease Genetics and by The Social Insurance Institution of Finland (funding to J. Kaprio), and by Helsinki University $\mathrm{PhD}$ funds (to M. Lehtovirta). Support also came from Helsinki University Central Hospital, Jalmari, and Rauha Ahokas and Yrjö Jahnsson Grants (to K. H. Pietiläinen). The authors thank R.C. Bonadonna for his valuable comments, A. Reunanen for providing the information on diabetes incidence in Finland, the late T. Klaukka and K. Koskenvuo for contributing to the compilation of the medication database, and G. Khalighi-Sikaroudi for participating in the assessment of diabetes status on the basis of medical records.
\end{abstract}

Duality of interest L. Groop has been a consultant for and served on advisory boards for sanofi-aventis, GSK, Novartis, Merck and Tethys Bioscience, and received lecture fees from Lilly and Novartis. All other authors declare that there is no duality of interest associated with this manuscript.

\section{References}

1. Hart CL, Hole DJ, Lawlor DA, Smith GD (2007) How many cases of type 2 diabetes mellitus are due to being overweight in middle age? Evidence from the Midspan prospective cohort studies using mention of diabetes mellitus on hospital discharge or death records. Diabet Med 24:73-80

2. Bouchard C, Tremblay A, Despres JP et al (1990) The response to long-term overfeeding in identical twins. N Engl J Med 322: $1477-1482$

3. Ridderstråle M, Groop L (2009) Genetic dissection of type 2 diabetes (review). Mol Cell Endocrinol 297:10-17

4. Thorleifsson G, Bragi Walters G, Gudbjartsson DF et al (2008) Genome-wide association yields new sequence variants at seven loci that associate with measures of obesity. Nat Genet 41:18-24

5. Willer CJ, Speliotes EK, Loos RJF et al (2008) Six new loci associated with body mass index highlight a neuronal influence on body weight regulation. Nat Genet 41:25-34

6. Zeggini E, Weedon MN, Lindgren CM et al (2007) Replication of genome-wide association signals in UK samples reveals risk loci for type 2 diabetes. Science 316:1336-1341

7. Frayling TM, Timpson NJ, Weedon MN et al (2007) A common variant in the FTO gene is associated with body mass index and predisposes to childhood and adult obesity. Science 316:889-894

8. Lyssenko V, Jonsson A, Almgren P et al (2008) Clinical risk factors, DNA variants, and the development of type 2 diabetes. N Engl J Med 359:2220-2232

9. Kaprio J, Koskenvuo M (2002) Genetic and environmental factors in complex diseases: the older Finnish Twin Cohort. Twin Res 5:358-365

10. North KE, Williams JT, Welty TK et al (2003) Evidence for joint action of genes on diabetes status and CVD risk factors in American Indians: the strong heart family study. Int J Obes Relat Metab Disord 27:491-497

11. Condon J, Shaw JE, Luciano M, Kyvik KO, Martin NG, Duffy DL (2008) A study of diabetes mellitus within a large sample of Australian twins. Twin Res Hum Genet 11:28-40

12. Kaprio J, Sarna S, Koskenvuo M, Rantasalo I (1978) The Finnish Twin Registry: formation and compilation, questionnaire study, zygosity determination procedures, and research program. Prog Clin Biol Res 24:179-184

13. Sarna S, Kaprio J, Sistonen P, Koskenvuo M (1978) Diagnosis of twin zygosity by mailed questionnaire. Hum Hered 28:241-254

14. Korkeila M, Kaprio J, Rissanen A, Koskenvuo M (1991) Effects of gender and age on the heritability of body mass index. Int $\mathrm{J}$ Obes 15:647-654

15. Kaprio J, Tuomilehto J, Koskenvuo M et al (1992) Concordance for type I (insulin-dependent) and type II (non-insulin-dependent) diabetes mellitus in a population-based cohort of twins in Finland. Diabetologia 35:1060-1067

16. Colditz GA, Willett WC, Rotnitzky A, Manson JE (1995) Weight gain as a risk factor for clinical diabetes mellitus in women. Ann Intern Med 122:481-486

17. Vazquez G, Duval S, Jacobs DR Jr, Silventoinen K (2007) Comparison of body mass index, waist circumference, and waist/ hip ratio in predicting incident diabetes: a meta-analysis. Epidemiol Rev 29:115-128

18. Weijnen CF, Rich SS, Meigs JB, Krolewski AS, Warram JH (2002) Risk of diabetes in siblings of index cases with type 2 diabetes: implications for genetic studies. Diabet Med 19:41-50

19. Frayling TM (2007) Genome-wide association studies provide new insights into type 2 diabetes aetiology. Nat Rev Genet 8:657662

20. McCarthy MI, Zeggini E (2009) Genome-wide association studies in type 2 diabetes. Curr Diab Rep 9:164-171 
21. Korkeila M, Kaprio J, Rissanen A, Koskenvuo M, Sorensen TIA (1998) Predictors of major weight gain in adult Finns: stress, life satisfaction and personality traits. Int J Obes 22:949957

22. Silventoinen K, Rokholm B, Kaprio J, Sørensen TIA (2010) The genetic and environmental influences on childhood obesity: a systematic review of twin and adoption studies. Int J Obes 34:2940

23. Stubbe JH, Boomsma DI, Vink JM et al (2006) Genetic influences on exercise participation in 37.051 twin pairs from seven countries. PLoS ONE 1:e22
24. Poulsen P, Kyvik KO, Vaag A, Beck-Nielsen H (1999) Heritability of type II (non-insulin-dependent) diabetes mellitus and abnormal glucose tolerance - a population-based twin study. Diabetologia 42:139-145

25. Keskitalo K, Silventoinen K, Tuorila H et al (2008) Genetic and environmental contributions to food use patterns of young adult twins. Physiol Behav 93:235-242

26. Alberti KG, Zimmet PZ (1998) Definition, diagnosis and classification of diabetes mellitus and its complications. Part 1: diagnosis and classification of diabetes mellitus provisional report of a WHO consultation. Diabet Med 15:539-553 